\title{
Smoking and Diabetes: A Case Control Study in a Rural Area of Kancheepuram District of Tamil Nadu.
}

\author{
Venkatachalam $\mathrm{J}^{1}$, Muthu Rajesh $\mathrm{E}^{2}$, Zile Singh ${ }^{3}$, Sarguna Devi ${ }^{4}$, Anil J Purty ${ }^{5}$ \\ Stalin $\mathrm{P}^{6}$, Jayaramachandran $\mathrm{S}^{7}$, Sathya $\mathrm{GR}^{8}$ \\ ${ }^{1,6}$ Assistant Professor, Department of Community Medicine, Pondicherry Institute of Medical Sciences. \\ ${ }^{2.7,8}$ Post Graduate student, Pondicherry Institute of Medical Sciences. \\ ${ }^{3,5}$ Professors, Department of Community Medicine, Pondicherry Institute of Medical Sciences \\ ${ }^{4}$ Intern, Department of Community Medicine, Pondicherry Institute of Medical Sciences
}

\begin{abstract}
Background: India was home to 62.4 million diabetics in the year 2011 and the incidence is on a continuous rise. Of the various risk factors for diabetes smoking is still under debate. Objectives: To assess the association between smoking and diabetes mellitus in a study population and to assess the association between socio demographic factors and diabetes in a study population.

Methodology: A community based case control study to associate smoking and diabetes was conducted in the rural area of Chunampet, Cheyyurtaluk of Kanchipuram district in Tamilnadu, which is under field practicing area, Rural Health Training Centre, Department of Community Medicine, Pondicherry Institute of Medical Sciences, Chunampet. Study participants: Adult population aged above 30 years of age. Sample size: Calculated using Epi info. 150 cases and 150 controls. Definition of cases: Known diabetics or persons with FBS > $126 \mathrm{mg} / \mathrm{dl}$ or RBS>140mg/dl. Definition of controls: Persons who are not a known a case of Diabetes and with FBS $<126$ or RBS $<140$. Exclusion criteria: Critically ill persons, persons with other comorbidities. Questionnaire: A pre-designed and pre-tested questionnaire was used. Details regarding diabetes history, smoking and other forms of tobacco were collected by house to house survey. Blood sugar was estimated using Accu-chek glucometer. Results: The study was conducted with 150 Diabetics (Cases) and 150 Non-Diabetics (Controls). Among the 150 Diabetics (Cases), 124 were males and 26 females. And, among the 150 NonDiabetics (Controls), 124 were males and 26 were females. Cases and controls are matched for sex and age ( \pm 5 years). $40 \%$ of current smokers and $41 \%$ of past smokers were found to be Diabetic while $19.34 \%$ of non smokers were diabetic. A positive association between smoking and diabetes was found (Odd's ratio=4.89, CI 95\% 3-8.5) and it was found to be statistically significant.
\end{abstract}

\section{Introduction:}

India was home to 62.4 million diabetics according to International Diabetes Federation in 2011. The number of deaths due to diabetes in the year 2011 was 983,000. India has the second largest number of diabetics next to China. The nationwide prevalence of diabetes is $9 \%$ and in southern cities it is as high as $20 \%{ }^{[1]}$. In western countries the onset of diabetes is at the age of 40's and 50's, but in our country the disease strikes much earlier. This will affect the economic growth and productivity of India. Few clinical and experimental reports have described the association between the active cigarette smoking, the development of diabetes, glycemic control, and diabetic complications. The outcomes of smoking such as hypertension, cardio vascular disorders, stroke, kidney disease, lung cancer, oral cancer etc are well documented. A positive association between smoking and diabetes was found in some studies ${ }^{[2,3]}$. Nicotine, acknowledged as the major pharmacologically active chemical in tobacco, has been found to be responsible for the association between cigarette smoking and development of diabetes ${ }^{[4,5]}$.

Most of the studies conducted to find the association between smoking and Diabetes were done on hospital basis. As smoking is a modifiable risk factor community based studies should be done to find the definite association between smoking and Diabetes to create Public awareness.

AIMS AND OBJECTIVES:

1. To assess the association between smoking and diabetes mellitus among a rural population of Kancheepuram district of Tamil Nadu.

2. To assess the association between socio demographic factors and diabetes among the same population.

\section{Methodology:}

Study Setting: A community based age ( \pm 5 years) and sex matched case control study to associate smoking and diabetes was conducted in the rural area of Chunampet, Cheyyurtaluk of Kanchipuram district in Tamil Nadu, 
which is under field practice area, Rural Health Training Centre under Department of Community Medicine, Pondicherry Institute of Medical Sciences. Study period: September 2012 to October 2012. Study participants: Adult population above 30 years of age. Sample size: Based on previous studies sample size was calculated using Epi info software and was found to be 123 for $95 \%$ CI. We selected 150 cases and 150 controls. Definition of cases: Known diabetics and persons with FBS $>126 \mathrm{mg} / \mathrm{dl}$ or RBS $>140 \mathrm{mg} / \mathrm{dl}$. Definition of controls: Persons who are not a known a case of Diabetes and with FBS $<126 \mathrm{mg} / \mathrm{dl}$ or RBS $<140 \mathrm{mg} / \mathrm{dl}$. Exclusion criteria: Critically ill person and Persons with other co morbidities. Sampling: All eligible participants were selected by doing house to house survey. 3 house visits were made and in case eligible subjects were not available on first visit revisit was being done. Subjects who refused and those who were non available despite 3 visits were excluded. Questionnaire: A pre-designed and pre-tested questionnaire was used. All subjects were interviewed in local language. Information about socio demographic profile, diabetic status, smoking habits, other forms of tobacco usage was collected. Blood sugar was estimated using Accu-chek glucometer which uses dependent glucose oxidoreductase mediator reaction. Diabetes was diagnosed if FBS $>126 \mathrm{mg} / \mathrm{dl}$ or PPBS $>200 \mathrm{mg} / \mathrm{dl}$. All interviews and tests were conducted by interns and post graduates under the supervision of faculties. Ethical Considerations: Informed verbal consent was obtained from the study participants before obtaining the data. Provision for referral and service were made for participants who were diagnosed newly as diabetics. Data Analysis and Statistical Methods:. The data were entered in the MS excel and analysis was done using SPSS 16. Proportions and Odd's ratio were calculated, Chisquare test was done. Statistical significance were referred to as $\mathrm{p}<0.05$.

III. Results:

Out of the 300 study subjects $248(82.7 \%)$ were men and 52(17.3\%) were women. Out of these subjects cases and controls are equally distributed in both sexes. Among these $155(51.66 \%)$ participants were in the age group 41-50, 106(35.33\%) were doing semi skilled occupation and $82(27.33 \%)$ were illiterate. The data from our study shows that professionals $(\mathrm{OR}=9)$ and graduates $(\mathrm{OR}=5.79)$ have higher odd's to develop diabetes when compared to other occupational and educational groups respectively. Interestingly out of 52 middle school subjects cases and controls are equal in number and also prevalence of diabetes was less among higher secondary education group when compared to other groups.

Table 1: Association between Socio Demographic Profile versus Diabetes

\begin{tabular}{|cccccc|}
\hline Gender & Cases & Controls & Total & Odd ratio & pValue \\
Males & 124 & 124 & $248(82.7 \%)$ & $*$ & 1 \\
Females & 26 & 26 & $52(17.3 \%)$ & & \\
Age & & & & & \\
$30-40$ & $30(48.4 \%)$ & $32(51.6 \%)$ & $62(100 \%)$ & & 0.9 \\
$41-50$ & $79(51 \%)$ & $76(49 \%)$ & $155(100 \%)$ & $*$ & \\
$51-60$ & $35(50.7 \%)$ & $34(49.3 \%)$ & $69(100 \%)$ & & \\
$61-70$ & $6(42.9 \%)$ & $8(57.1 \%)$ & $14(100 \%)$ & & \\
Occupation & & & & & \\
Unemployed & $20(32.8 \%)$ & $41(67.2 \%)$ & $61(100 \%)$ & Reference & \\
Unskilled & $30(39 \%)$ & $47(61 \%)$ & $77(100 \%)$ & 1.31 & \\
Semiskilled & $66(62.3 \%)$ & $40(37.7 \%)$ & $106(100 \%)$ & 2.36 & 0.001 \\
Skilled & $27(57.4 \%)$ & $20(42.6 \%)$ & $47(100 \%)$ & 2.77 & \\
Professional & $7(87.5 \%)$ & $2(22.2 \%)$ & $9.0(100 \%)$ & 7.17 & \\
Education & & & & & \\
Higher secondary & $14(34.1 \%)$ & $27(65.9 \%)$ & $41(100 \%)$ & Reference & \\
Illiterate & $36(46.1 \%)$ & $46(56.1 \%)$ & $82(100 \%)$ & 1.51 & \\
Primary & $21(48.8 \%)$ & $22(51.2 \%)$ & $43(100 \%)$ & 1.84 & \\
Middle school & $26(50 \%)$ & $26(50 \%)$ & $52(100 \%)$ & 1.93 & 0.01 \\
High school & $44(62.9 \%)$ & $26(37.1 \%)$ & $70(100 \%)$ & 3.26 & \\
Graduates & $9(75 \%)$ & $3(25 \%)$ & $12(100 \%)$ & 5.79 & \\
\hline
\end{tabular}

Among the subjects $110(36.66 \%)$ were smokers out of which 81 were diabetics which shows that smokers are at higher risk to develop diabetes $(\mathrm{OR}=4.89,95 \%$ CI 3-8.5). Cigarette usage (80\%) was more prevalent than beedi among smokers. But beedi smokers were at higher risk to develop diabetes $(\mathrm{OR}=24.55)$ compared to non smokers and cigarette smokers. Also those who smoke $>10$ cigarettes $(\mathrm{OR}=7.15)$ and for $>20$ years $(\mathrm{OR}=12.86)$ have higher chance to develop diabetes when compared to non smokers and moderate smokers. The prevalence of other forms of tobacco was comparatively less only 22 subjects use other forms of tobacco (chewing and snuff) out of which 17 were diabetics (OR=3.71). 


\begin{tabular}{|c|c|c|c|c|c|}
\hline $\begin{array}{l}\text { Characteristic } \\
\text { Smoking status }\end{array}$ & Cases & Controls & Total & Odds Ratio & $P$ value \\
\hline Smokers & $81(73.63 \%)$ & $29(26.37 \%)$ & $110(100 \%)$ & \multirow{2}{*}{4.89} & \\
\hline Non smokers & $69(19.34 \%)$ & $121(80.66 \%)$ & $190(100 \%)$ & & 0.001 \\
\hline \multicolumn{6}{|l|}{ Type of Smoking } \\
\hline Non smoker & $69(19.34 \%)$ & $121(80.66 \%)$ & $190(100 \%)$ & Reference & \multirow{3}{*}{0.01} \\
\hline Cigarette & $56(80 \%)$ & $24(20 \%)$ & $80(100 \%)$ & 4.09 & \\
\hline Beedi & $28(93.33 \%)$ & $2(6.67 \%)$ & $30(100 \%)$ & 24.55 & \\
\hline \multicolumn{6}{|l|}{ No of Cigarettes } \\
\hline Non smoker & $69(19.34 \%)$ & $121(80.66 \%)$ & $190(100 \%)$ & Reference & \multirow{3}{*}{0.001} \\
\hline$<10$ cigarettes & $28(63.63 \%)$ & $16(36.37 \%)$ & $44(100 \%)$ & 3.07 & \\
\hline$>10$ cigarettes & $53(80.3 \%)$ & $13(19.7 \%)$ & $66(100 \%)$ & 7.15 & \\
\hline \multicolumn{6}{|l|}{ Duration } \\
\hline $\begin{array}{r}\text { Nonsmokers } \\
<10 \mathrm{yrs}\end{array}$ & $\begin{array}{c}69(19.34 \%) \\
24(58.5 \%)\end{array}$ & $\begin{array}{c}121(80.66 \%) \\
17(41.5 \%)\end{array}$ & $\begin{array}{c}190(100 \%) \\
41(100 \%)\end{array}$ & $\begin{array}{l}\text { Reference } \\
2.48\end{array}$ & \multirow{2}{*}{0.001} \\
\hline $11 \mathrm{yrs}-20 \mathrm{yrs}$ & $36(81.4 \%)$ & $8(18.6 \%)$ & $44(100 \%)$ & 7.67 & \\
\hline$>20$ years & $22(88.0 \%)$ & $3(12 \%)$ & $25(100 \%)$ & 12.86 & \\
\hline \multicolumn{6}{|l|}{$\begin{array}{r}\text { Other forms of } \\
\text { Tobacco }\end{array}$} \\
\hline Yes & $17 \quad(77.27 \%)$ & $5(22.73 \%)$ & $22(100 \%)$ & \multirow{2}{*}{3.71} & \multirow{2}{*}{0.008} \\
\hline No & $133(47.84 \%)$ & $145(52.16 \%)$ & $278(100 \%)$ & & \\
\hline
\end{tabular}

\section{Discussion:}

From our study we found that among socio demographic factors occupation and educational level may be associated with diabetes. As professional and highly educated persons have higher prevalence of diabetes when compared to other groups. This may be due their sedentary life style. This pattern is entirely different from developed countries where the prevalence is more among lower education and occupational groups ${ }^{[6,7,8]}$. But studies in India reveal those highly educated and higher socio economic groups are at higher risk ${ }^{[9,10]}$. So this implies public awareness regarding diabetes risk factors is needed among all socio economic and educational groups.

We also found that smoking is an independent risk factor for development of diabetes ( $\mathrm{OR}=4.89,95 \%$ CI 3-8.5). This positive relationship between smoking and diabetes had been found in previous studies ${ }^{[1,12]}$. Also this relation was found to be dose dependent as persons smoking > 10 cigarettes/day were found to be at higher risk $(\mathrm{OR}=7.15)$ when compared to light smokers. We also found that there is 5 times increased risk of developing diabetes in people smoking more than 20 years $(\mathrm{OR}=5.18)$. This dose dependent relationship was found in previous prospective studies ${ }^{[13,14,15]}$. Beedi smoking is clearly a predominantly male practice and is more prevalent in rural than urban areas of India. Our study shows that beedi which have higher nicotine content compared to cigarette poses more risk for development of diabetes $(\mathrm{OR}=24.55)$. This very high Odd's ratio suggests that nicotine may be the culprit behind the association between smoking and diabetes. Persons with other forms of tobacco usage (chewing and snuffing) also have significant risk for developing diabetes (Odd's ratio=3.71). From this we can conclude that tobacco both in smoke and smokeless form is an independent risk factor for diabetes.

All these results were obtained after adjusting for age and sex and found to be statistically significant. Since smoking had not yet been proved a definite risk factor for diabetes this study implies the importance to create public awareness regarding the risk. And also further studies have to be done to find the biological cause for this relation. Strict legislative measures for controlling smoking and sale of tobacco products should be made keeping in mind that diabetes affects the productive age group and the continuous rise in prevalence will adversely affect the economic status of our country.

\section{References:}

[1] Priya Shetty. India's Diabetic time bomb. Nature 2012; 485: 14-15.

[2] Deng H. Cigarette smoking and Diabetes mellitus: A case control study in Guandong, China. Available from URL: http// hu.hku.hk/bib/B31636846.

[3] Radzeviciene L, Ostrauskas R. Smoking and the risk of type 2 diabetes mellitus: A case control study. Available from URL: http// www.ncbi.nim.nlh.gov/pubmed/19269874.

[4] Eliasson B. Cigarette smoking and diabetes. Prog Cardiovasc Dis 2003; 45: 405-13. | PubMed | ChemPort .

[5] Facchini FS, Hollenbeck CB, Jeppesen J, Chen YD, Reaven GM. Insulin resistance and cigarette smoking. Lancet 1992; 339: 112830. | Article | PubMed | ISI | ChemPort |.

[6] Siobhan C Maty, Susan A Everson-Rose, Mary N Haan, Trivellore E Raghunathan and George A Kaplan. Int J Epidemiol. 2005 December ; 34(6): 1274-1281. 
[7] Stringhini S, Tabak A, Akbaraly T, Sabia S, Shipley M, Marmot M et al. BMJ 2012;345:e5452

[8] Maty S, James S, Kaplan G. American Journal of Public Health 2010; 100: 137-145.

[9] Agarwal S, Ebrahim S. Public Health Nutrition: 15(6), 1065-1077

[10] Kinra S, Lyngdoh T, Prabaharan D, Reddy K, Ramakrishnan L, Gupta R et al. BMJ 2010;341:c4974

[11] Morton G, Garret M, Reid J, Wingrad D. Current Smoking and Type 2 Diabetes Among Patients in Selected Indian Health Service Clinics, 1998-2003. American Journal of Public Health 2008; 98: 560-65.

[12] Wannamethee SG, Shaper AG, Perry IJ; British Regional Heart Study. Smoking as a modifiable risk factor for type 2 diabetes in middle-aged men. Diabetes Care 2001; 24: 1590-5.

[13] Will JC, Galuska DA, Ford ES, Mokdad A, Calle EE. Cigarette smoking and diabetes mellitus: evidence of a positive association from a large prospective cohort study. Int J Epidemiology. 2001; 30: 540-6.

[14] Zhang L, Curhan G, Frank B, Eric B, John P. Association between active and passive smoking and incident of type 2 diabetes in women. Diabetes care 2011; $34: 892-97$.

[15] Thomas K Houston, Sharina D Person, Mark J Pletcher, Kiang Liu, Carlos Iribarren, Catarina I Kiefe :Active and passive smoking and development of glucose intolerance among young adults in a prospective cohort: Cardia study.BMJ, doi:10.1136/bmj.38779.584028.55

\section{Contributions:}

Venkatachalam J: Conception and design of the study; planning and conducting the study; analysis and interpretation of data; and drafting the paper.

Muthu Rajesh.E: Design of the study, drafting the paper and revising the draft critically for substantial intellectual content.

Zile Singh: Design of the study; planning and coordinating the study;

Stalin $\mathbf{P}$ conception and design of the study

Sarguna Devi, Analysis and interpretation of data

Jayaram Chandran S: Helps in preparation of questionnaire

Anil J purty, G R.Sathya :-drafting the paper and revising the draft critically for substantial intellectual content.

\section{Conflict of Interest:- None. Role of Funding Source:- Pondicherry Institute of Medical Sciences}

Acknowledgements:-

The authors would like to thank Dr.Punitha for arranging study instruments, Prof Joy Bazroy for providing moral support and guidance for this study. The authors want to extend thanks to interns (October -2012) for helping in data collection and data entry. Also extend thanks to Dr. Arun, Dr .Sivaraj RMOs, RHTC Chunampet for their cooperation. 